\title{
Uma nova volta à "nova volta da espiral": movimentos do signo
}

\author{
A new return to the "new round of the spiral": movements of the sign
}

\author{
Roselene de Fatima COITO \\ Universidade Estadual de Maringá (UEM) \\ https://orcid.org/0000-0002-8386-9611
}

\begin{abstract}
RESUMO: Em comemoração aos 50 anos do lançamento do livro "Arqueologia do Saber" (1969/1986), escrito pelo filósofo Michel Foucault, este artigo tem como objetivo fazer um retorno ao livro "As Palavras e as Coisas - uma arqueologia das ciências humanas" (1966/2000), para esmiuçar, em aspectos pontuais, a importância dos movimentos do signo na composição do percurso de Foucault, naquilo que ele toma como constituição do saber nestas duas arqueologias. Para tanto, lançamos mão, também, das reflexões de Gilles Deleuze na leitura que ele faz, num primeiro movimento, do que se pode entender como enunciado, já que para ele a "Arqueologia do Saber" é a teoria dos enunciados. Diante disso, propomos, nos movimentos do signo, discutir o enunciado, o signo e a linguagem como constitutivos de uma ordem que estabelece paradigmas do que se toma como ciência e como arte, sem, no entanto, desconsiderar que, seja num paradigma ou noutro, há o foco do poder.
\end{abstract}

PALAVRAS-CHAVE: movimentos do signo; signo; linguagem; enunciado.

ABSTRACT: In commemoration of the 50th anniversary of the book "Archaeology of Knowledge" publication, written by the philosopher Michel Foucault, this article aims to return to the book "The Order of Things: an archaeology of the human sciences". We plan to scrutinize, in specific aspects, the importance of the sign movements in the composition of Foucault's path related to what he understands as the constitution of knowledge in these two archaeologies. Therefore, we also consider Gilles Deleuze's reflections in his readings, in a first movement, of what is understood as the statement, since for him the "Archaeology of Knowledge" is the theory of the statements. Thus, our proposition, in the sign movements, is to discuss the statement, the sign and the language as constitutive of an order that establishes paradigms of what is considered to be science and art, without disregarding that, in one paradigm or in another, there is the focus of power.

KEYWORDS: sign movements; sign; language; statement. 


\section{Introdução}

Foi assim que comecei a escrever As palavras e

as coisas... Era uma espécie de material morto que eu percorria um pouco como uma espécie de jardim desértico...

"O belo perigo", Michel Foucault

O livro "A Arqueologia do Saber" completou 50 anos de sua publicação no ano de 2019. Esta obra se faz inesgotável em cada leitura, tendo em vista a complexidade filosófica na abordagem realizada por Michel Foucault. Na contracapa do livro, ele se justifica dizendo da necessidade de um retorno - "como que por uma nova volta de espiral” - para dar significação à palavra arqueologia.

Com que propósito escrevi este livro? Para explicar o que quis fazer nos livros precedentes em que tantas coisas ficaram obscuras? Não só, nem exatamente, mas, indo um pouco mais longe, para retornar, como que por uma nova volta de espiral, a um ponto anterior ao que havia empreendido: mostrar de onde eu falava; demarcar o espaço que torna possíveis estas pesquisas e outras talvez que jamais concluirei; em suma, para dar significação à palavra arqueologia que eu havia deixado vazia (FOUCAULT, 1986, s/p).

Neste retorno, sua busca está em dar significação à palavra arqueologia, que, na obra anterior, "As Palavras e as Coisas - uma arqueologia das ciências humanas" (2000) - havia ficado vaga. Seu objetivo em "A Arqueologia do Saber" é descrever discursos, estes entendidos como conjuntos, ao mesmo tempo, familiares e enigmáticos que se tornam conhecidos, através do tempo, como a medicina, a economia política ou a biologia. Para tanto, debruça-se sobre as coisas ditas em seus níveis de especificidade, como as suas condições de aparecimento, as suas formas de acúmulo e encadeamento, as suas regras de transformação e suas descontinuidades. Ainda de acordo com o filósofo, o domínio das coisas ditas é o que se chama de arquivo e o papel da arqueologia é analisá-lo. (FOUCAULT, 1986). E este domínio das coisas ditas, Deleuze (2017) lê como aquilo que se refere às formações históricas.

Como podemos ver, Foucault já aponta neste comentário o caminho que seguirá para abordar a descrição destes discursos ${ }^{1}$. Diante disso, o filósofo assevera ao leitor que buscará, ao descrever estes discursos, a unidade na dispersão, caminho diferente dos

${ }^{1}$ Descrever não é o mesmo que enunciar, como veremos adiante. 
historiadores que seguem a linearidade temporal do discurso, marcando sua posição de filósofo e não de historiador. Sobre esta diferenciação, Deleuze (2017) cita, em seu livro "Michel Foucault: as formações históricas", a Nova Escola - Escola dos Annales, que propõe uma história dos comportamentos e das mentalidades. Ainda de acordo com este autor, a "A Arqueologia do Saber" é uma teoria dos enunciados, é uma disciplina de arquivos que combina o visível e o enunciável. Em outros termos, o regime do ver é uma condição de tudo o que faz uma época, ao passo que o regime do dizer é a condição de todas as ideias de uma época. Nesse sentido, diferentemente da Nova Escola, não é uma história do comportamento e das ideias que interessam a Foucault, mas sim como se dá visibilidade aos comportamentos e enunciabilidade às ideias.

Diante do posto, faremos uma nova volta à "nova volta da espiral", isto é, discutiremos os movimentos do signo na constituição das epistemes dos séculos XVI, XVII e XVIII no livro "As Palavras e as Coisas - Uma arqueologia das ciências humanas" relacionando as duas arqueologias. Nesta direção, trazermos o que Foucault toma como enunciado, tendo em vista que, desses movimentos do signo, o filósofo propõe a constituição do saber.

Foucault deixa claro, em sua trajetória filosófica, as suas idas e vindas nas reflexões que propôs ao longo de sua pesquisa. Por isso, concordamos com o filósofo português Edgardo Castro (2014), quando pauta os estudos de Foucault como torções e que fica difícil estabelecer fases distintas do percurso do filosófico francês, quando aborda a questão tanto do poder quanto do saber. Em "As Palavras e as Coisas-Uma arqueologia das ciências humanas", a abordagem da constituição do saber se volta para os movimentos do signo na arte e na ciência. No domínio da arte, com o texto literário "Dom Quixote", de Cervantes, e com a pintura de "As meninas", de Velásquez, o homem é colocado em evidência e em "A Arqueologia do Saber", no que tange às reflexões sobre o enunciado, os discursos da ciência tomam o homem como objeto do saber científico e como tal, produzem modos de subjetivação deste sujeito. Diante do exposto, é que vem a proposta de pensarmos os movimentos do signo nas duas arqueologias, sem desconsiderar que ambas se tecem e se alimentam uma da outra, naquilo que trazem como a constituição do saber.

\footnotetext{
${ }^{2}$ Aqui estamos abordando apenas a primeira parte do livro de Deleuze que surgiu de suas aulas.
} 


\section{Nos movimentos do signo: o enunciado, o signo e a linguagem na constituição do saber.}

Tomando esta relação estabelecida entre as arqueologias propostas por Foucault, discutindo, na constituição do saber, o signo em seu percurso, Deleuze (2017) propõe que o saber se constitui no agenciamento das visibilidades e das enunciabilidades e que elas não são dadas imediatamente, mesmo se vendo tudo e se dizendo tudo. Cabe ao analista extrair aquilo que se faz ver e aquilo que se diz em cada época, não porque há ocultação, mas porque há regras de formação que constituem os limiares ${ }^{3}$ das visibilidades e das enunciabilidades.

Nesse sentido, podemos dizer que Deleuze (2017) toma a constituição do enunciado a partir de estratos que se dão como empilhamentos de limiares diversamente orientados. Isso não quer dizer que o enunciado equivalha a uma palavra, a uma frase ou ainda a uma proposição, como o próprio Foucault aponta em “A Arqueologia do Saber”, após ter levantado hipóteses sobre o que seria uma formação discursiva. Em tais hipóteses, ao trazer o conceito de formações discursivas, assevera que tentou "descrever relações entre enunciados" e que viu problemas por ter feito uma utilização "grosseira dos termos enunciado, acontecimento e discurso" (FOUCAULT, 1986, p.35). Para ele, o propósito de levantar as hipóteses seria pensar neste conjunto discursivo que se constitui de enunciados formadores dos objetos do discurso. Por isso, posteriormente, neste mesmo livro, o filósofo indaga: "Se o enunciado é a unidade elementar do discurso, em que consiste? Quais os seus traços distintivos? Que limite devemos nele reconhecer?” (1986, p.91). A partir disso, Foucault dá o exemplo de duas proposições que têm a mesma estrutura proposicional, mas apresentam caracteres distintos. No mesmo exercício de reflexão, o filósofo propõe pensar se frase e enunciado são a mesma coisa, dizendo que caracteres gramaticais da frase não são suficientes para definir um enunciado; por fim, traz a questão dos atos de fala e, ao tratar do ato ilocutório, mostra que também esse conceito não daria conta de definir o que é um enunciado. $\mathrm{O}$ estudioso afirma que "a língua e o enunciado não estão no mesmo nível de existência", tendo em vista que a língua é um "sistema de construção para

\footnotetext{
${ }^{3}$ Deleuze toma a palavra limiar como um nível a partir do qual um enunciado pode ser qualificado como tal ou qual. (2017, p. 55)
} 
enunciados possíveis" e que ela existe "a título de descrição obtida a partir de um conjunto de enunciados reais" (FOUCAULT, 1986, p. 96-97).

Diante desta assertiva, definir o enunciado se torna um exercício complexo e pra isso é necessário considerar alguns fatores: a) entender o enunciado como função de existência que pertence, exclusivamente, aos signos e, a partir deles, se fazem sentido ou não, segundo regras que se sucedem ou se justapõem, se sua formulação é oral ou escrita; b) Como uma função, cruza um domínio de estruturas e unidades possíveis e faz aparecer conteúdos concretos no tempo e no espaço (FOUCAULT, 1986, p. 98 e 99).

Para entender essa afirmativa, Deleuze (2017) destaca a necessidade de entender as regras de formação dos enunciados, isto é, a determinação do estrato (formações históricas), a família a qual pertence (biologia - evolucionista e antievolucionista, por exemplo, os enunciados não pertencem à mesma família) e a determinação do limiar (político, jurídico, estético). Ele assevera que, se conhecermos as regras de formação dos enunciados em um determinado domínio, nada nos será ocultado e propõe que o exercício do analista é extrair o enunciado.

Deleuze define "A Arqueologia do Saber" como um composto de visível (daquilo que é posto) e de enunciável (aquilo que é produzido). Em sua percepção eles (visível e enunciável) são elementos do saber e não são imediatamente legíveis, por isso, sua necessidade de extração de um dado corpus, de um domínio determinado, formado por um conjunto de palavras, frases e proposições que se compõem a partir de regras de formação e que se dão como uma regularidade. No entanto, isso não basta, segundo ele, pois é preciso fixar um método, por meio de focos de poder que produzem e organizam as palavras, as frases e as proposições. Para ele, Foucault não explicita o método em "A Arqueologia do Saber", mas na "Vontade do Saber - História da Sexualidade I"'

Sobre o corpus, Deleuze recorre a Foucault em dois momentos: "Em As palavras e as Coisas- uma arqueologia das ciências humanas", quando Foucault discute o ser da linguagem e em "A Arqueologia do Saber" quando propõe que "a linguagem na instância do seu aparecimento e de seu modo de ser, é enunciado" (Deleuze, 2017, p. 105). Aqui, precisamos fazer dois esclarecimentos. O primeiro é definir o que vem a ser o ser da linguagem. Em "As palavras e as Coisas - uma arqueologia das ciências humanas" (2000), no capítulo II - “A prosa do mundo”, Foucault discute como se dá o 
sistema de signos no mundo ocidental. Esta reflexão parte da inquietação e do riso que provoca em Foucault um texto de Borges sobre uma certa enciclopédia chinesa. Borges, ao categorizar os animais, de acordo com Foucault, deslumbra outra taxinomia dos signos, o que leva à transgressão de toda imaginação, de todo pensamento possível e que apresenta como fio condutor a série alfabética. Ao fazer circular sua enumeração, Borges, segundo o filósofo, faz com que o possível não seja a vizinhança das coisas, mas o lugar onde elas poderiam avizinhar-se, já que "em toda cultura, entre o uso do que se poderia chamar os códigos ordenadores e as reflexões sobre a ordem, há a experiência nua da ordem e dos seus modos de ser" (FOUCAULT, 2000, p. XVIII).

Foucault afirma que "As Palavras e as Coisas" tem como objetivo mostrar no que veio a se tornar esta experiência desde o século XVI, em uma cultura como a nossa. Outrossim, ele diz que quer trazer à luz o campo epistemológico para entender a episteme, em que os conhecimentos enraizaram sua positividade (uma história de condições de possibilidade) e "as configurações que deram lugar às formas mais diversas do conhecimento empírico", no espaço do saber (2000, p. XIX).

há duas grandes descontinuidades na epistême ocidental: aquela que inaugura a idade clássica (por volta dos meados do século XVII) e aquela que, no início do século XIX, marca o limiar de nossa modernidade, [dizendo que] A ordem sobre cujo fundamentos pensamos, não tem o mesmo modo de ser que a dos clássicos (FOUCAULT, 2000, p. XIX).

Seu intuito é pensar o sistema de signos na linguagem, pois o ser da linguagem se constitui de signos. Porém, para pensar este sistema de signos e chegar ao que Foucault toma como ser da linguagem, ele parte para a discussão de como era pensada a similitude e de como ela poderia organizar as figuras do saber. $\mathrm{O}$ francês trata de quatro similitudes, já que, até o final do século XVI, foi a semelhança que desempenhou um papel construtor no saber da cultura ocidental. Essas similitudes são a convinientia, o aemulatio, a analogia e a simpatia, são exploradas na cultura ocidental, pelo fato de ditarem os modos em que o mundo se dá para que as coisas possam se assemelhar.

Tais similitudes são assinaladas na superfície das coisas e o saber delas se dá nas assinalações e na sua decifração. Então, é uma linguagem formada de signos e é a semelhança que constitui o signo no "seu singular valor de signo" (FOUCAULT, 2000, p. 39), ou seja, ele, o signo, tem semelhança com o que indica, mas esta semelhança serve para reconhecer a primeira, que por sua vez é patenteada por uma terceira. É um 
jogo de paralelismos de semelhanças que, no saber do século XVI, tem na semelhança a sua universalidade e, enquanto tal, a busca pelo sentido é trazer à luz o que se assemelha, é buscar uma lei dos signos para descobrir o que é semelhante (FOUCAULT, 2000, p.40). Contudo, a semelhança nunca é estável em si mesma, pois os elementos do saber funcionam por adição e se condenam a se conhecer sempre a mesma coisa. Nesse sentido, signos e semelhanças se imbricavam, fazendo com que micro e macrocosmo aparecessem como garantia do saber, o qual, neste século XVI, acolhe magia e erudição. Assim, o conhecer será a interpretação, já que a linguagem vale como o signo das coisas.

Nesta perspectiva, a linguagem não é um sistema arbitrário, mas deve ser estudada como uma coisa da natureza, e a gramática deste século (XVI) baseia-se na ciência da natureza ou nas disciplinas esotéricas, conforme Foucault. O filósofo discorre sobre todas as implicações dessa linguagem não-arbitrária, trazendo elementos que a constituíram, partindo, também, de um campo religioso místico, para quem a linguagem é "entendida não como um episódio na história da língua, mas como uma experiência cultural global" que se deu "no interstício entre o Texto primeiro e o infinito da Interpretação" (FOUCAULT, 2000, p. 57).

Após esta discussão da linguagem no século XVI, em que os signos formam a linguagem em um sistema de semelhança, o filósofo passa a discutir como o sistema de signos, a partir do século XVII, desempenha seu papel na construção do saber. Ele tratará do sistema do signo quando foi ternário - no estoicismo e no Renascimento -, e quando se torna binário. Ao tratar do sistema ternário no estoicismo, o filósofo mostra que, neste sistema, reconhecia-se o significante, o significado e a "conjuntura". Já no Renascimento, a organização ternária é mais complexa, pois a semelhança é tanto a forma dos signos quanto seu conteúdo e apela tanto para as marcas como para as assinalações quanto para as similitudes que se resolvem numa única figura, a qual se dá na experiência da linguagem.

A linguagem se dá em três níveis, a partir do ser único da escrita: no seu ser bruto e primitivo, no comentário e no texto. Em contrapartida, no século XVII, PortRoyal traz a disposição binária do signo, ou seja, a ligação do signo se dá entre significante e significado. Contudo, com essa nova disposição do sistema dos signos, pergunta-se, então, não mais como a linguagem se dá como escrita material das coisas, 
mas como o signo pode estar ligado àquilo que ele significa. Segundo Foucault (2000, p. 59), a resposta a esta pergunta envolve dois momentos, a Idade Clássica e o pensamento moderno. Na Idade Clássica, ela se dá pela análise da representação, e, no pensamento moderno, pela análise do sentido e da significação ${ }^{4}$. Diante disso, as palavras e as coisas vão se separar e "o discurso terá realmente por tarefa dizer o que é, mas não será nada mais do que ele diz" (FOUCAULT, 2000, p. 59). Assim acontece a imensa reorganização da cultura da qual a Idade Clássica foi a primeira etapa. No entanto, Foucault assevera que, talvez, a literatura manifeste o reaparecimento do ser vivo da linguagem, já que, nos séculos XVII e XVIII, toda linguagem valia como discurso. Este reaparecimento do ser vivo da linguagem, ao longo do século XIX até os dias atuais, de Hölderlin, Mallarmé a Antoin Artaud, vem na medida em que se constitui como uma espécie de contradiscurso:

A literatura é o que compensa (e não o que confirma) o funcionamento
significativo da linguagem. Através dela o ser da linguagem brilha de
novo nos limites da cultura ocidental - e em seu coração- pois ele é,
desde o século XVI, aquilo que lhe é mais estranho; porém, desde esse
mesmo século XVI, ele está no centro do que ela recobriu. ...A partir do
século XIX, a literatura repõe à luz a linguagem no seu ser: não, porém,
tal como ela ainda aparecia ainda no final do Renascimento. Porque
agora não há mais aquela palavra primeira... doravante a linguagem vai
crescer sem começo, sem termo e sem promessa... (FOUCAULT, 2000,
p.60-61).

Diante do posto, podemos ver que a reflexão de Foucault, com relação ao signo e ao sistema de signo, desemboca no ser da linguagem, ou, como diz Deleuze (2017), no "há linguagem", como uma forma de estabelecer a organização das figuras do saber, saber este que varia, que faz do ser da linguagem um ser histórico, tendo na literatura aquilo que vai em uma outra ordem ou des-ordem do discurso vigente - da ciência, da religião, da política. Seu ponto de partida para pensar o ser da linguagem foi a inquietação diante da enciclopédia chinesa de Jorge Luís Borges, ponto que voltaremos a discutir com Foucault.

Com relação à segunda explanação de Deleuze sobre a linguagem para pensar o que seria o enunciado em Foucault, ou seja, a linguagem na instância do seu aparecimento e de seu modo de ser há uma longa reflexão, que aqui traremos mais

\footnotetext{
${ }^{4}$ No capítulo "representação" de As palavras e as Coisas, Foucault detalha o percurso do estudo do signo na construção e constituição do saber nos itens III, IV, V e VI, sendo que explanaremos com atenção o VI item para o entendimento do literário, a partir da leitura que ele realiza de Dom Quixote, em relação ao que Foucault toma como "projeto de uma ciência da ordem".
} 
pontualmente para o propósito deste artigo, que é pensar a relação o ser da linguagem e o enunciado nos movimentos do signo. Conforme foi dito anteriormente, descrever e enunciar não são a mesma coisa, pois, de acordo com Deleuze (2017), Foucault realiza os dois: descreve quadros, descreve arquiteturas como o asilo e a prisão, onde se dá a visibilidade da loucura e do crime, respectivamente. Ainda de acordo com Deleuze, "enunciar não é fazer o exercício empírico da linguagem; é constituir enunciados", tendo em vista que "os enunciados são as condições para o desdobramento de todas as redes de ideias que operam em uma época”. (DELEUZE, 2017, p.28 e 29). Além de os enunciados serem condições desse desdobramento, Deleuze afirma que o enunciado é uma regularidade.

Voltando à questão da linguagem, tomando-a na instância de seu aparecimento e de seu modo de ser, para uma definição (possível) do enunciado, temos aqui um desdobramento do pensamento de Foucault sobre a linguagem, qual seja, a linguagem como um direcionamento do mesmo e do diferente deflagrando o ser da linguagem em uma combinação sígnica, e o ser da linguagem como "a linguagem numa dimensão do fala-se, do murmúrio anônimo, isto é, do enunciado" (DELEUZE, 2017, p. 114).Como podemos ver, há uma complexidade na relação entre e/ou possível definição de enunciado, de signo e de linguagem.

Conforme propõe Foucault (1986, p. 98), entender o enunciado é considerar que se trata de "uma função que pertence, exclusivamente, aos signos e, a partir deles, se eles fazem sentido ou não, segundo que regras se sucedem ou se justapõem e se sua formulação é oral ou escrita". Então, se o enunciado é uma função que pertence exclusivamente aos signos, como compreender o que Foucault está propondo como signo, neste caso?

Arriscamos caminhar com Deleuze (2017) para pensar o que seria signo nesta definição de enunciado como função dos signos. Como já mostramos anteriormente, Deleuze lê o percurso de produção filosófica de Foucault, até mesmo para esmiuçar para seus alunos em quais leituras Foucault se balizava para fazer as suas propostas filosóficas, como visualidades e enunciabilidades, afirmando que, sem abordar, em uma análise, as visualidades (formações não-discursivas), a análise de um corpus fica alijada. Ao trazer as visualidades, Deleuze vai apontando como Foucault traz à luz, faz ver os comportamentos de uma época e, ao fazê-lo, mesmo que Foucault tenha o objetivo 
explícito de constituir uma teoria do enunciado em "Arqueologia do Saber", faz alusões às visibilidades.

Seguindo no caminho das visibilidades, discutindo a diferença entre processo (quando Foucault realiza a descrição das máquinas em Roussel) e procedimento (quando a descrição feita das máquinas em Roussel como um procedimento linguístico), percebe-se o dualismo com suas nuances, em Foucault, de acordo com Deleuze. Para pensar este dualismo em suas nuances, Deleuze (2017) se apropria da teoria linguística de Hjelmslev, em que o signo se constitui do plano de expressão (rebatismo do significante) e do plano de conteúdo (significado), inclusive para "justificar" o termo forma-prisão que Foucault utiliza em "Vigiar e Punir" (2005). Ainda com Deleuze, Foucault mostrará que, de certa forma, o plano de expressão não se refere ao significante, e o plano do conteúdo não se refere ao significado. O que seria, então, "uma forma de expressão numa dada formação histórica? Um regime de enunciados. E um plano de expressão? A prisão" (DELEUZE, 2017, p. 27). Nessa perspectiva, a forma-prisão seria uma forma de conteúdo, o direito penal seria a forma de expressão, conforme Deleuze lendo Foucault.

Além disso, a forma de expressão em Foucault não tem nada a ver com o significante, e a forma de conteúdo, com o significado. As visibilidades não se reduzem ao significante, assim como os enunciados não se reduzem ao significado.

A análise do discurso, assim entendida, não desvenda a universalidade de um sentido; ela mostra à luz do dia o jogo da rarefação imposta, com um poder fundamental de afirmação. Rarefação e afirmação, rarefação, enfim, da afirmação e não generosidade contínua do sentido, e não monarquia do significante (FOUCAULT, 1999, p.70, grifos nossos).

Nessa definição, a Análise do Discurso "não desvenda a universalidade de um sentido", tal qual assim se fazia no século XVI, e "não generosidade contínua do sentido e não monarquia do significante", conforme Port-Royal e teorias linguísticas do século XIX e XX. Outrossim, mesmo a ciência caminhando nessa dualidade, ver e falar não se reduzem uma à outra e nem as visibilidades e nem as enunciabilidades existem prontas, pois variam em cada época, tendo em vista os movimentos do signo no campo do saber. No entanto, ao definir enunciado como função exclusiva de signos e o ser da linguagem colocando a ordenação dos signos para tratar da dimensão da linguagem em seu modo de ser, Foucault não nega o signo, mas mostra como se constrói o saber de cada época, e 
isso não se desvincula de como o signo se dá, seja no enunciado, seja na língua, seja na linguagem.

\section{Nos movimentos do signo: a linguagem, a literatura e a pintura}

Foucault não abandona o signo, mesmo porque é a partir dos movimentos do signo, do século XVI até os dias atuais, o meio no qual se constrói o saber, como visto anteriormente. No capítulo "representar", de "As palavras e as Coisas" (2000), ao tratar de Dom Quixote, ele retoma/amplia a discussão sobre o signo e a linguagem que desenvolve no prefácio deste livro, quando apresenta o conto de Borges. Seguindo os passos tomados por Foucault nessa obra, passamos a discutir a relação linguagem/signo, quando o filósofo trata da "novela romanesca" Dom Quixote 5 .

Ao abordar a representação nos séculos XVI e XVII, ele afirma que Dom Quixote tem como ser interior a linguagem, que ele é feito de palavras, que ele se constitui de signos e a sua busca é saber quais signos dar a si próprio e aos outros, pois ele é da mesma natureza do texto donde saiu e é semelhante a todos estes signos que ele decalcou. Nesse decalque sígnico, torna-se legível e não visível como os seres. A façanha deste herói de si mesmo é, segundo Foucault, transformar a realidade em signo, e, nesta semelhança, os signos são conforme as próprias coisas.

Dom Quixote inscreve-se no signo da semelhança, semelhança esta da desrazão e da imaginação. O saber do século XVI é um conhecimento misturado e sem regra, onde todas as coisas do mundo podiam se aproximar das experiências, das tradições e das culturas, o ponto de partida do filósofo francês para pensar a inauguração do homem na episteme da modernidade e, posteriormente, dos discursos da ciência sobre a loucura. No século XVII, com as postulações de Renè Descartes, a semelhança é recusada em nome da comparação, dando ao saber uma nova configuração universalizante e analítica, ao invés de analógica. Toda semelhança será submetida à prova da comparação. Não se aproximam mais as coisas, mas se busca a diferença. Então, o texto deixa de fazer parte dos signos e das formas de verdade. A linguagem entra na era da transparência e da neutralidade.

\footnotetext{
${ }^{5}$ Esta discussão é uma pequena parte do capítulo produzido por mim, cujo título é "No ser da linguagem literária, o regime estético da imagem: a constituição da história dos (des)afetos", que se encontra no livro "No campo discursivo", organizado por Atílio Butturi Jr et al, pela editora Pontes Editores, Campinas/SP, em 2020.
} 
A grande mudança da episteme ocorreu com o advento da teoria de Descartes, em que o signo passa a ter uma função empírica e o estudo da natureza sígnica se apresenta como algo natural - designa o que reflete - ou convencional - aquilo que designa uma ideia. Nesse sentido, a eficácia do signo se faz no domínio dos conhecimentos empíricos. Contrariamente a isso, no século XVI era a linguagem que instaurava a sua função significante. Havia uma circularidade, um dobra do signo sobre si mesmo. Não havia uma busca pela fidelidade, nem pela probabilidade do signo. $\mathrm{O}$ binarismo do signo instaurado na época clássica segue um caminho contrário aos estoicos e aos primeiros gramáticos gregos, conforme já apontamos anteriormente. Há uma extensão universal do signo no campo da representação, fazendo com que este perca seu valor de meios de conhecimentos e chaves para um saber. Para Foucault, filosoficamente, a semelhança é fundamental, porque ela é a dobradura do mundo, o recôndito da imaginação e um murmúrio vago das similitudes. A imaginação também é uma das propriedades da natureza humana, e a semelhança, um dos seus efeitos.

No entanto, no final do século XVIII, por um lado, se instauram as disciplinas formais e, por outro, a história e a semiologia, mas esta é absorvida por aquela, e o saber passa a ser "a transparência perfeita das representações nos signos que as ordenam". (FOUCAULT, 1999, p. 105). Portanto, a representação não se dá mais numa opacidade do falar e do ver, mas em sua transparência. Contudo, de acordo com a leitura que Deleuze (2017) realiza dos textos de Michel Foucault, o dizível e o visível não são da mesma ordem, como procuramos detalhar no item anterior. Refletindo sobre as propostas de Foucault, Deleuze explana o que é esta ordem do dizível e do visível. Segundo ele, quando Foucault discute o enunciado, deixa evidente que não se trata de algo plenamente dado. Podemos entender esta afirmação de Deleuze em dois movimentos de leitura que Foucault realiza das artes plásticas, quais sejam: da tela de Velásquez e das telas de Magritte.

A tela de Velásquez tinha como enunciado inicial "A família real”. Embora este enunciado propusesse que a família do rei estava em evidência, o foco central da tela eram as meninas, as infantas, e no primeiro plano da tela o próprio pintor pintando. Então, o enunciado que dá título à tela não está plenamente dado; há uma ruptura na hegemonia do sentido. No entanto, a tela muda de título; de "A família real" para "As meninas". Mesmo as infantas estando no foco central da tela, há um pintor olhando para 
fora da tela. Há um mise en abyme nessa representação da tela: quem vê quem? Quem é real? Ou ainda: o que é o real? Então, nesse jogo de imagens, de sombra e de luz, de angulações possíveis, o enunciado não é plenamente dado, e a hegemonia do sentido se rompe, instaurando possibilidades do ver e do dizer sobre aquilo que se dá a ver e sobre a multiplicidade daquilo que se dá a dizer. Nesse sentido, a representação se dá como uma apresentação de possibilidades do ver e do dizer, condição inaugural para o que Foucault toma como modernidade. Dito de outra forma, na tela o homem é o foco das atenções, seja aquele que vê, seja aquele que é visto, mesmo quando o enunciado que intitula a tela muda, pois que a família real, as infantas e o pintor focalizam, num jogo de sombra e de luz, o homem ${ }^{6}$.Aqui também cabe apontarmos brevemente "a nãopessoa" em Foucault. De acordo com Deleuze (2017, p 11-114), Foucault vai contra o "eu falo", "isso fala" e o "mundo fala", porque a linguagem para ele se dá em uma dimensão, na dimensão do ser da linguagem, já que o murmúrio anônimo é o enunciado, o qual não é plenamente dado.

Outro movimento em que o enunciado não é plenamente dado, acontece quando Foucault analisa as telas "A traição das imagens" e "Isto não é um cachimbo", ambas de Renè Magritte. Na primeira tela em questão, há dois cachimbos pintados como se um fosse a cópia do outro que, por sua vez, seria a cópia de um outro no "mundo real". Quais destas imagens traem o nosso olhar? Se aqui o enunciado verbal não trai as imagens, as imagens traem o nosso olhar. Há, novamente, e de uma outra forma, a quebra da hegemonia do sentido, e o enunciado anunciado não é plenamente dado. Embora possamos pensar que esta tela é a representação de algo real, as imagens traem nosso olhar, já que há dois cachimbos pintados. Então, o que seria a representação? Na tela se dá a ver uma representação que apresenta e coloca em xeque o que é a própria representação, pois que temos não uma semelhança da coisa, mas as coisas em similitude, isto é, a coisa em experiência da própria coisa. Se, em "Dom Quixote", de Cervantes, e na tela, “As meninas", de Velásquez, temos a linguagem em um movimento do signo que inaugura a episteme da modernidade ao colocar o homem em

\footnotetext{
${ }^{6}$ Foucault não nega o homem nem o indíviduo, mas critica o humanismo que toma o homem como um ser real e ao mesmo tempo da transcendental, tal qual o postulado por Heiddger. Só para completar o entendimento desta crítica ao humanismo, Deleuze (2017, p. 63) diz: "uma das bases da crítica ao humanismo em Foucault tem sua origem na crítica do discurso do filantropo. Crítica não é desbloquear os segredos, mas as regras às quais estes tipos de enunciados obedecem”.
} 
foco, na tela, "A traição das imagens", o movimento do signo é outro, isto é, ele constituirá experiência do ser da linguagem, experiência esta que problematiza o real, ao instaurar entre desenho (imagens) e enunciado (título da tela) um jogo sígnico. Neste jogo se questiona mesmo a existência do homem, pois, se existe o real, o homem nele existe, nele experiencia e nele vive.

E, por fim, a tela "Isto não é um cachimbo", em que há o enunciado que nega e a imagem que afirma. Aqui, a negação e a afirmação suspendem o significante e o enunciado não se dá plenamente, se se considerar a hegemonia do sentido trazendo também à baila o questionamento do que é o real, já que a imaginação se apoia nos signos da semelhança e tem como seu momento positivo o murmúrio vago dos signos da similitude. Em outras palavras, há nesse jogo entre o dizer e o mostrar uma ruptura de sentido, levando-se em consideração que aquilo que é dito nega aquilo que é mostrado. Mais uma vez, por meio dos elementos sígnico que compõem a tela, Magritte deixa em suspenso a inquietação diante do que pode se entender como real e, enquanto tal, o homem nele e diante dele, isto é, daquilo que é falado e daquilo que é visto na suspensão do significante e na ruptura do sentido hegemônico.

Pode-se dizer, a partir destes breves apontamentos, que falar e ver não se apresentam na mesma ordem; pertencem a ordens diferentes. Contudo, mais do que ver, o que interessa a Foucault é entender como se dá visibilidade às coisas, estas que traem, que negam e que afirmam, tendo em vista que, no espaço da tela, assim como no espaço arquitetônico como a prisão, por exemplo, traçam-se movimentos do olhar que olha para aquilo que se dá a ver e o que se dá a ver se situa no campo da visibilidade. Nestes movimentos do olhar que vê aquilo que se dá a ver, os signos deflagram que, enquanto signos, nos seus movimentos, ultrapassam uma catalogação/categorização taxinômica.

Diante do que dissemos, o representar é um apresentar, um apresentar de palavras e de coisas, não de palavras que servem a uma taxinomia, mas uma ordem outra, qual seja, a desordem do discurso vigente. E de coisas que são, ou não, coisas que se dão a ver. No entanto, é necessário voltar ao texto de Foucault para entender o que ele toma como taxinomia, já que o texto "Enciclopedia chinesa", de Jorge Luis Borges, incita o filósofo francês a pensar as palavras e as coisas na constituição do saber.

No item VI, do capítulo "Representar", intitulado "Máthêsis e "taxinomia", assim inicia: 
Projeto de uma ciência geral da ordem; teoria dos signos analisando a representação; disposição em quadros ordenados das identidades e das diferenças: assim se constituiu na idade clássica um espaço de empiricidade que não existira até o fim do Renascimento e que estava condenado a desaparecer desde o início do século XIX (FOUCAULT, 2000, p. 99).

Quando Foucault aponta neste início do item VI, do Capítulo "Representar", do que tratará, refere-se à constituição do saber a partir de categorias e distribuição mascaradas e deturpadas por nós, tendo em vista que nem o homem, nem a natureza e nem a vida se nos oferecem espontaneamente. No entanto, o que a episteme clássica possibilita é um conhecimento da ordem e a álgebra ordena, pela máthesis, a natureza simples, e a taxinomia ordena, ao instaurar um sistema de signos, as naturezas complexas. Nesse projeto da ciência geral da ordem, a taxinomia (signos) se reporta à máthesis, e a máthesis é um caso particular da taxinomia, esta que implica um continuum das coisas (plenitude do ser) e uma certa potência da imaginação que traz luz ao contínuo como um estabelecimento da ordem. No entanto, na episteme clássica, além da ciência da ordem calculável (máthesis), há a constituição das ordens, a partir de sequências empíricas (gênese) e ambas se estendem à região do signo que possibilita a representação.

Segundo o filósofo, nessas regiões se encontram a história natural (caracteres que articulam a continuidade da natureza e sua imbricação), a teoria da moeda e do valor (ciência dos signos que autoriza a troca e estabelece equivalências) e a Gramática geral (ciência dos signos no reagrupamento das singularidades de percepção e recorte do movimento dos pensamentos). Portanto, são nos domínios da máthesis, da taxinomia e da gênese que o saber se instaura, mas um saber que tem um limite: "a transparência perfeita das representações nos signos que as ordenam" (FOUCAULT, 2000, p. 105). Nisso reside o fato de o estudioso rir da enciclopédia chinesa de Borges, na qual os signos produzem uma ordem outra: a des-ordem.

Para Foucault, a literatura é "o que compensa o funcionamento significativo da linguagem" e "a partir do século XIX, a linguagem no seu ser reposta pela literatura" (FOUCAULT, 2000, p. 60-61), é no seu ser que o signo, como função de existência, dá ao enunciado um sentido ou não, estabelece regras de justaposição e sucessão e cruza domínios de estrutura e unidades possíveis. É na literatura, a linguagem ao infinito, que o funcionamento significativo se dá, não porque a literatura seja o poder, mas porque ela 
é um dos seus efeitos ${ }^{7}$, como bem colocou Foucault em seus estudos sobre a literatura. Enquanto tal, ela oferece ao saber uma outra ordem, a ordem do ser do signo, que tem como função dar existência à, pois que tanto a literatura quanto a pintura vêm estabelecer uma outra ordem do discurso, isto é, uma ordem em que a catalogação/categorização do signo não é suficiente para abarcar a complexidade nem da linguagem e nem do enunciado.

\section{Considerações finais}

Fazer o exercício da reflexão com Foucault demanda um pensar profundo e um olhar atento, ambos demorados, que exige em cada leitura uma nova leitura. Sua proposta nos desafia a quebrar paradigmas e incendiar o pensamento. Por isso, buscamos com essas reflexões parar e pairar sobre Foucault, juntamente com Deleuze. E, ao ler Foucault sempre nos questionamos: como este zigzag filosófico dispersivo mantém a unidade e como se dá a sua regularidade? Essa foi, então, a proposta deste artigo: fazer uma nova volta "a uma nova volta da espiral" para entendermos, nas duas arqueologias, como pensar os movimentos do signo e como estes movimentos são traçados, já que destes movimentos parte, a nosso ver, a proposta da constituição do saber.

Adentrar nos movimentos do signo, em "As palavras e as Coisas- uma arqueologia das ciências humanas" (2000), foi fundamental para entender como se constituiu o saber a partir do e no(s) século(s) XVI, XVII e XVIII. No entanto, Deleuze aponta para o sentido rigoroso da palavra epistemologia, ou seja, epistemologia “concernente à experiência" (2017, p.55) e o saber não se reduz ao conhecimento devido aos limiares em que um enunciado pode ser qualificado enquanto tal ou qual. Também pensar os movimentos do signo, em "A Arqueologia do Saber", compreendendo-a enquanto uma prática discursiva, é entender o ser do signo enquanto uma função que dá existência a enunciados e aos modos de ser do enunciado, já que "O significante faz parte e, somente faz parte, segundo as direções que a linguagem

\footnotetext{
7“"A vida dos homens infames”. In: Estratégias, poder-saber. Ditos e escritos IV. Rio de Janeiro: Forenseuniversitária, 2003.
} 
propõe", e portanto, “a designação, a significação e o significante são apenas direções da linguagem" (DELEUZE, 2017, p.107) e não a linguagem em seu ser.

Por isso que, Foucault, segundo Deleuze (2017, p. 108), invoca Nietzsche, Mallarmé e Artaud, ao dizer que quem pode responder no final do século XIX à linguagem não é nem a linguística (que desmembrou tudo), nem a representação, mas a literatura. Conforme Deleuze, "A literatura que assume esta função de congregação da linguagem. A literatura que, a partir do final do século XIX tem a especificidade de um poder" (DELEUZE, 2017, p.108), porque ela congrega a linguagem "do fora" de toda representação possível e porque nela está o "há linguagem” ou ser da linguagem.

Logo, podemos dizer que os signos nos seus movimentos constituem o ser da linguagem e o ser do signo. Enquanto ser da linguagem constitui o seu próprio ser enquanto linguagem; como ser do signo cumpre a função de existência e de condição de existência dos enunciados, que nos seus modos de ser, dão visibilidade e enunciabilidade à, cruzando, assim, como anteriormente citado, "um domínio de estruturas e unidades possíveis fazendo aparecer conteúdos concretos no tempo e no espaço". (FOUCAULT, 1986, p. 98 e 99).

\section{Referências}

CASTRO, Edgardo. Introdução a Foucault. Trad. Beatriz de Almeida Magalhães. Belo Horizonte: Editora Autêntica, 2014.

DELEUZE, Gilles. Michel Foucault: formações históricas. Trad. Claudio Medeiros e Mário Marino. São Paulo: n-1 edições e editora filosófica Politeia, 2017.

FOUCAULT, Michel. As palavras e as coisas - Uma arqueologia das Ciências Humanas. Trad. Salma Tannus Muchail. $8^{\mathrm{a}}$ Ed e $2^{\mathrm{a}}$ tiragem. São Paulo: Martins Fontes, 2000 , p. $23-62$.

FOUCAUlT, M. A Arqueologia do Saber. Trad. Luiz Felipe Baeta Neves. $2^{\mathrm{a}}$ Ed. Rio de Janeiro: Forense-Universitária, 1986. Contracapa e p. 89-99. 
FOUCAUlT, M. A ordem do discurso. Aula inaugural no Collège de France, pronunciada em 2 de dezembro de 1970. Trad. Laura F.A. Sampaio, São Paulo: Edições Loyola, 1999.

FOUCAULT, M. “A vida dos homens infames”. In: Estratégias, poder-saber. Ditos e escritos IV. Rio de Janeiro: Forense-universitária, 2003.

FOUCAULT, M. Isto não é um cachimbo. Trad. Jorge Colli. $1^{a}$ Ed. São Paulo: Paz e terra, 2014.

FOUCAULT, M. Vigiar e Punir. Rio de Janeiro: Editora Vozes, 2005. 